\section{Gender and Higher Educa- tion: Increasing Exposure of Harassment and Pay Gaps}

\section{Ellen Hazelkorn}

Ellen Hazelkorn is professor emerita and director of the Higher Education Policy Research Unit (HEPRU), and education policy consultant, BH Associates, Ireland. E-mails: ellen.hazelkorn@dit.ie and info@ bhassociates.eu.

A rape trial involving a young woman, at the time I9 years old, and two well-known Irish rugby players in early 2018 had the island of Ireland mesmerized. Unlike such trials in the Republic of Ireland, rape cases in Northern Ireland come under UK legal jurisdiction. Hence, not only were the identities of the accused known, but the explicit sexual details were reported upon daily. The woman's identity was supposed to be hidden, but she was quickly identified and social media went into over-drive. After nine weeks, the two men, and their friends, were all acquitted. As commentators said, it is a court of law where guilt needs to be proven beyond a reasonable doubt, and not a court of morals or laddish behavior.

It was a \#MeToo moment of sorts. Rallies were held, \#IBelieveHer trended at number one, and the Dublin Rape Crisis Centre reported an increase in calls. The level of public outrage clashed with the level of tolerance normally displayed to issues of sexual harassment and gender discrimination.

\section{Sexual Harassment on Campus}

Sexual harassment on college campuses tends to get less attention, despite occasional media reports about the need to tackle the "epidemic" of harassment by staff toward students, and students against students. The Guardian (6 March 20I7) conducted a survey in 2OI7 showing that UK students had made at least $\mathrm{I} 69$ allegations of sexual misconduct against university staff between 20II and 20I7. At least another I27 allegations were made about staff by colleagues.

According to Universities UK, progress tackling student-to-student harassment is most effective where there is active senior leadership, but less progress has been made in tackling hate crime, hate-based harassment, and staffto-student sexual misconduct. While the overall results correspond with a study by the National Union of Students (NUS), the latter focused its attention on power relations within the academy, and particularly on staff-student sexual misconduct.
Bullying and harassment, including sexual harassment, have also been issues on Irish campuses. Universities have a discipline code, but the general view is that students are adults and should take responsibility for their own actions-which lets the university off the hook. The codes, which include staff, cover sexual harassment, physical violence, bullying, cheating or plagiarism, and smoking indoors. In extreme cases, students can be expelled. In 20I7, The Irish Times (6 November 20I7) reported a number of cases involving students, most of which involved complaints against men.

These issues have prompted a wider public conversation about sex education, especially around the concept of "consent." In Ireland, the minister for education has announced a major review of relationship and sexuality education (RSE) in primary and second-level schools. Universities in Ireland and the United Kingdom are prescribing "consent" training for incoming freshmen. The National University of Ireland Galway (NUIG) Smart Consent training workshops aim to "help you explore the different dimensions of consent."

On a professional level, I am familiar with cases involving power relationships between graduate students and supervisors. Such behavior affects male as well as female students; it is often normalized and difficult to monitor. There are also instances when the culture of discourse descends into what I call verbal rape. In the case of one-to-one music or vocal teaching, as in conservatoires, or during the course of student mentoring, windows had to be placed in doors, or doors left open, as a protection for all concerned. The issues become even more complicated where dual-sector institutions or facility sharing practices bring school and university students together for an enriched learning environment or simply efficiency gains, but with very different behavioral guidelines required.

There is a huge reluctance to bring forward cases where one's integrity or conduct may be questioned or future career prospects threatened, especially for women. While there have always been individual cases, college sexual harassment has been slower to garner attention in Europe than in the United States. Ultimately, a lack of research, combined with a lack of understanding, means the full scale is unknown, and universities lack basic guidelines. Narrow definitions of excellence also shape organisational culture and academic behavior.

\section{Gender Pay Gap}

Promotion and pay is a different matter. As one of the few women holding a vice-presidential position in Ireland over the last 20 years, I can attest to the slow pace of change. In fact, as women progress through a typical academic career path, they become increasingly underrepresented compared to men. The data is indisputable. 
The EU publishes SHE Figures, which monitor the gender dimension in research and innovation across the European Union. In 2002, the share of tertiary graduates was similar for both sexes, however the percentage of female graduates has since grown by almost twice the rate. In 20I6, the gender gap in the European Union, meaning the proportion of women aged 30-34 that had attained tertiary education, exceeded men by 9.5 percent, with women outnumbering men in almost all member states.

Yet, women earn on average 16 percent less than men. Only 20 percent of heads of European higher education institutions are women. In 20I3, women were 2I percent of top-level researchers, having made very limited progress since 2010. Among scientific and administrative board leaders, women constitute only 22 percent, and 28 percent of board members. The greatest variability is at professorial level, with most EU countries having institutions with no female full professors.

\section{Bullying and harassment, including sex- ual harassment, have also been issues on Irish campuses.}

The gender pay gap recently made headlines in the United Kingdom when 2018 figures were published. This refers to the difference between the average earnings of men and women, expressed relative to men's earnings. While it may not tell us anything we did not already knowthat men dominate top earning positions-the results are striking. The median pay gap is 9.8 percent nationally, but I8.4 percent among universities. Women in two universities are paid 37.7 percent less than men. As the $\mathrm{BBC}$ reported, of the prestigious Russell Group, Durham University fares worst with a 29.3 percent gap.

In Ireland, the Higher Education Authority (HEA) published the National Review of Gender Equality in Irish Higher Education Institutions (2016), with wide-ranging recommendations. There has never been a female president since the first university was established ca. 426 years ago, and there are currently only two female presidents in the institute of technology sector. The figures are particularly acute by discipline, with the greatest discrepancy in science, technology, engineering, maths, and medicine (STEMM). Professorial appointments have provoked great outcry, with a landmark award being given to a woman at NUIG by the Equality Tribunal in 2009, on the grounds of gender discrimination.

Yet, Ireland is also an example of what can happen when policy and funding drive behavior. The Athena SWAN
Charter was established in the United Kingdom in 2005 to encourage and recognize commitment to advancing the careers of women in STEMM. It has since been expanded to all disciplines and adopted in Ireland. There are three award levels, bronze being "entry level," certifying institutions' commitment to the ro key principles, and requiring a critical self-analysis and action plan. Most significantly, the three Irish research funding councils have made it a requirement that an HEI achieves the bronze by 2019, and a silver by 2023 , to be eligible for research funding.

As a result, all HEIs are actively engaged in appointing a vice-president for equality, diversity, and inclusion, and busy making appointments at the senior level. Training is being introduced to address unconscious bias, and is required for senior management. But progress is very slow. It could take decades to reach the recommended gender balance of 40 percent. Hence, there is talk of quotas. The take-away is that nothing moves institutions faster than money. I am getting over my frustration with women being appointed simply to meet new regulations-but have we not had that experience with men for decades.

DOI: http://dx.doi.org/I0.6oI7/ihe.20I8.94.I05I5

\section{Sexual Violence in Ethiopian Higher Education}

\section{AyenACHEW A. WOLDEgIYORgIS}

Ayenachew A. Woldegiyorgis is a doctoral candidate and graduate assistant at the Center for International Higher Education, Boston College, US. E-mail:woldegiy@bc.edu.

T igher education in Africa is in the grip of sexual vio1 lence. For example, one of the continent's leading institutions, Makerere University in Uganda, recently made international headlines for the appalling revelations of a two month-long investigation that shook the whole institution. A closer look at the situation in Ethiopia can help understand the nature and extent of the problem.

\section{An InSTITUTIONAL EXAMPLE}

Hanna Tefera had been the director of the University Gender Affairs Directorate at Adama Science and Technology University since November 20I3. On January I8, 20I8, she received a letter of dismissal from her position for unstated reasons. Tefera said her removal was sudden and she did not know anything as to why. Meanwhile, Addis Standard reported that Tefera's removal was related to a case she was 